\title{
Intelligent BIM record model for effective asset management of constructed facility
}

\author{
Hossain Md Aslam ${ }^{1, *}$ and Haron Ahmad Tarmizi ${ }^{2}$ \\ ${ }^{1}$ Dept. of Civil Engineering, Nazarbayev University, Astana, Kazakhstan \\ ${ }^{2}$ Faculty of Civil Engineering and Earth Resources, University Malaysia Pahang, Kuantan, Malaysia
}

\begin{abstract}
Asset management is a continuous process that runs throughout the lifecycle of a constructed facility. The current practice of asset management is paper-based consisting of manual inspection and proves to be time consuming, tedious, and prone to human error. Building Information Modelling (BIM) has been found to be an emerging technology and core of information management for the design, construction, operation and maintenance (O\&M) process. Though the usefulness of BIM has been greatly realized in the AEC (Architecture, Engineering and Construction) industry, its use for O\&M, particularly in asset management, is still in its infancy. This research describes a framework of an intelligent BIM record model that can capture all the assets in BIM during the construction of a building facility. All the information necessary for operation and maintenance along with the location would be stored in a database integrating with the BIM. The database library can be interrogated with BIM and serves as a repository of asset management for the built facility. The BIM record model would help to take informed decisions regarding operations, maintenance, servicing, repair and replacement of an asset hence saving labour-intensive asset inventory, time and money, and preventing the wastage of unnecessary tools acquisition.
\end{abstract}

\section{Introduction}

Asset management is of great importance since from the owner's perspective, $85 \%$ of the total project cost is spent in operation and maintenance (O\&M) [1] and it encompasses the longest phase of any building facility. As stated by Buang [2], "Under the 10th Malaysian Plan, an estimated budget of RM230 billion is allocated for development projects inclusive of repairs, maintenance, upgrading and renovation of assets". This shows the Government's commitment to ensure that assets are better managed, continuously upgraded and properly maintained for maximum life. Nevertheless, from the audit report, it was found that there were many instances of wastefulness, extravagance and mismanagement which indicate that the public funds had not been wisely spent. Though the Public Work Department (PWD) has introduced MySPATA, an electronic-based asset management solution, the database is not integrated with $3 \mathrm{D}$ models and requires manual inspection, making it

\footnotetext{
* Corresponding author: md.hossain@nu.edu.kz
} 
difficult to locate the actual onsite position of the asset, which is tedious and time consuming. Literature reveals that this is common in traditional asset management which is mostly paper-based with manual inspection, and proves to be inefficient, tedious and prone to human error [3-5]. BIM has emerged as the core of information management that can generate, consolidate and maintain an integrated database for the design, construction, operation and maintenance process in the AEC industry [6,7]. The usefulness of BIM has been greatly realized in the AEC industry and has been well deployed in design and construction. Similarly, BIM can be beneficial for asset management during O\&M in many ways, such as cost-effective retrofit decisions, better facility management, safe O\&M related repair works, organized demolition, etc. [8]. However, BIM application in O\&M or facility management (FM) is very limited and yet to be fully exploited [5,9,10].

Love et al. [11] described the importance of investing in BIM for the asset owners. Research is ongoing concerning BIM for operation and maintenance for effective asset management. Motamedi et al. [12] used RFID tagging to locate fixed and movable assets in a building. Costin [13] also described a method of passive RFID location tracking for visualization in BIM. Though RFID tracking and visualization in BIM is useful to locate an asset in a 3D model, a comprehensive database of assets integrated with BIM would be beneficial for facility managers to effectively manage the assets throughout the lifecycle of the facility. BIM can provide a tool which can retain the records of all the updated data of the built asset [14]. Nevertheless, it is necessary to understand the information needs of FM professionals before requirement documents are refined [15].

Considering the aforementioned issues of functionalities, interoperability, and information requirement for the owner and FM personnel, the primary focus of this research is to describe a framework of an intelligent BIM record model for integrated asset management of building facilities. The BIM Record Model will be developed in generalized ways so that the application can be expanded to manage the assets of any constructed building facilities for both the public and private sector.

\section{BIM integrated asset management challenges}

Major drawbacks in realizing the potential of BIM in asset management during O\&M are functionalities and interoperability issues. For example, not all asset and O\&M related information is compatible for hosting in a BIM environment [16]. Possible reasons as found in existing literature are inconsistent naming conventions, inadequate techniques to capture building facilities and assets, lack of knowledge about information necessary for O\&M and FM, and poor information synchronization $[4,9,17,18]$. To eliminate the interoperability issues between the BIM used for design and construction and the BIM to be used for O\&M, COBie (Construction Operations Building Information Exchange) and several other researchers [7,19-21] have been working in developing new data standards for BIM projects. Although number of studies had been done to identify and categorize the required information in BIM necessary for FM as well as process of developing FM-enabled BIM, asset-related information is different for various building facilities depending on FM functions, how assets are managed by O\&M personnel, legislative requirements, etc. [7,9]. Moreover, owners and FM personnel have limited experience and knowledge of using and updating BIM as necessary for asset management $[7,22]$. Hence, it is important to develop a generalized framework of a BIM record model that can capture all the asset related information necessary for O\&M as the building facilities are constructed and ready to be used by the owners and FM personnel. 


\section{Model development}

Following the aforementioned BIM integrated asset management challenges, the specific aim of this research is best described through the system architecture that comprises three key components as shown in Fig. 1. The first is tagging and tracking assets using RFID which can spot facility items, store relevant information of these items and continuously update the information in real-time. The second is a reasoning algorithm and user interface to capture the asset's information and link it into the BIM model. The third is a database that stores all the information of the asset, which is integrated with the BIM model. The information may include, but is not limited to, the unique identification number, physical dimensions, location, material, warranty, user manuals, maintenance schedule, servicing, and safety specification. Once the asset database is developed with a BIM Record Model, it can be used for asset management during the operation and maintenance lifecycle of a constructed facility.



Fig. 1. System architecture of BIM record model.

\section{Framework for intelligent BIM record model}

The intelligent BIM record model can be elaborated following the three key components as shown with the system architecture in Fig. 1. The detail of the framework for the intelligent BIM record model is shown in Fig. 2 with a systematic interaction between different components. The proposed system has at its core in a BIM model. 


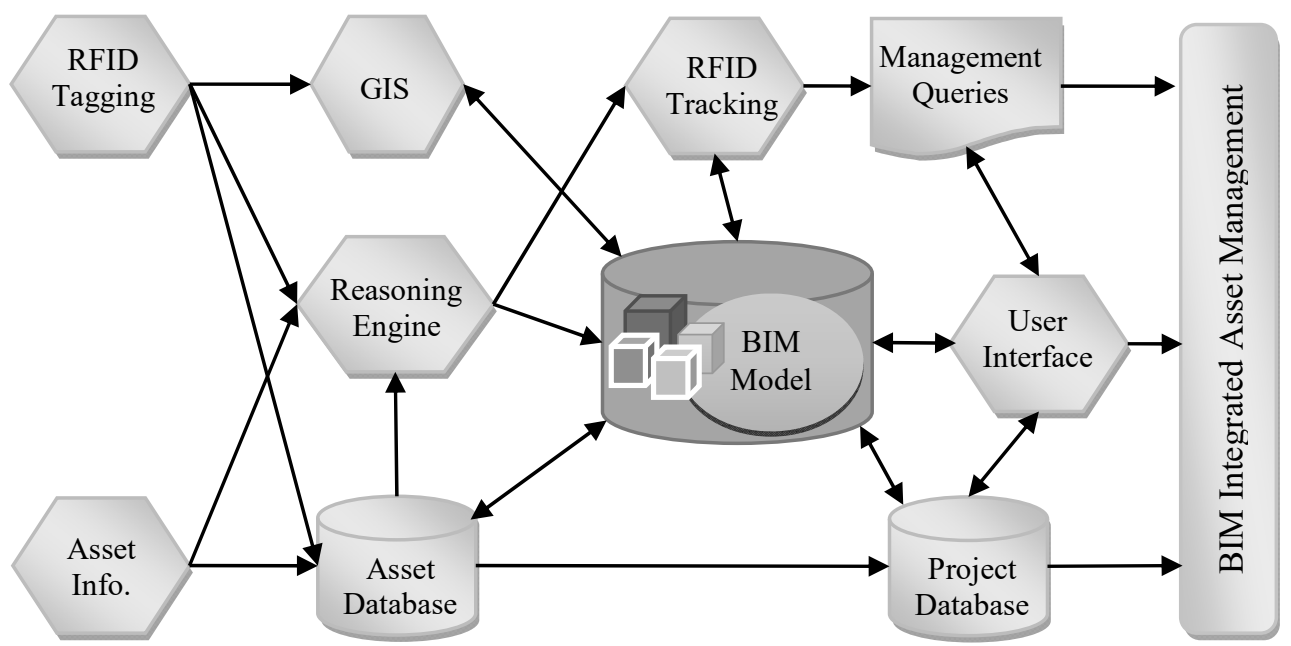

Fig. 2. Framework for intelligent BIM record model.

Assets are to be tagged with Passive RFID tagging since it is found to be more suitable for an indoor application of tracking due to their small size, low cost and low maintenance requirements compared to Active RFID [13]. Relevant maintenance information as necessary for commonly used assets can be gathered through existing literature, case studies $[3,7,9,21]$, and semi-structure interviews with experts and practitioners. Not all the information of an asset should be stored in an RFID tag due to the limited storage capacity of Passive RFID. Additional information (e.g. the user manual, warranty, safety specification) of the asset are to be stored in a separate database and can be linked with their unique RFID tag ID. The RFID tag ID is also linked with the asset's GUID (Globally Unique Identifier) of the BIM in order to visualize the asset in a 3D model. Hence, the tag is used to extract the information of the asset once they are installed and store it in a database linked with the BIM model. RFID tracking can be done during the operation and maintenance stage of the facility lifecycle.

Assets can be interrogated in the BIM model with a reasoning engine. The reasoning engine reads open-BIM format 3D model (such as IFC) integrated with the asset [23,24]. Geographic Information System (GIS) can be used to obtain the actual location of the asset and position them in the BIM model. This is particularly important for large-scale projects and to enhance city/country-wide energy performance [25,26]. After that, a User Interface (UI) would boost the extraction of asset info, link with the BIM and store them in the database. For the ease of use, the UI can easily be configured with handheld smart devices such as smart phones, Tabs, iPads, or PDAs. Such mobile-BIM applications are increasing at various phases of construction projects as well as O\&M [27,28].

In the proposed BIM record model, two databases have been designed in MySQL/MS Access: one is general for commonly used assets in the constructed facility and the second one is a project specific database for asset management integrated with the BIM model. An asset's specific information can be retrieved from the asset database to be used for any project. The file format for the BIM model will be in IFC (.ifc) since different companies may build their BIM using different a BIM platform (e.g. Revit, Tekla Structure, ArchiCAD) and all the platforms have their import and export facilities in .ifc format.

The project database can be developed for asset management with the facility to be fully maintained, i.e. additions, modifications and deletes will be supported. The database library may be interrogated with the BIM model and serve as a repository of asset management for the built facility. 
Once the database is ready integrated with the BIM using the proposed BIM record model, a management query system would facilitate the asset management during the operation and maintenance lifecycle of a facility. This will include real-time tracking and visualize them on the BIM model, automatic scheduling for maintenance and servicing, investigating the necessity of repair and replacement, updating asset information, and so on.

\section{Conclusion and discussion}

Traditional asset management techniques are mostly manual with $2 \mathrm{D}$ drawings and fragmented asset data which is found to be tedious, time consuming and prone to human error. Efforts had been made to improve the asset management procedure with FM-enabled BIM. Nevertheless, use of BIM in asset management is limited and restricted by functionality and interoperability issues, the lack of a uniform technique to capture asset data to be used in BIM, poor information synchronization, etc. This paper presents a generalized framework of an intelligent BIM record model that can capture and store relevant asset information necessary for proper and efficient asset management during O\&M of building facilities. The proposed BIM record model will enhance the building's asset database integrated with an open-BIM format 3D model with the facility of tagging and tracking the asset onsite through RFID.

The proposed framework has not been tested and validated with any building project since the authors are working on identifying and categorizing owners' information requirements for BIM-enabled asset management based on FM functions, legislative requirements and others, and will describe this in a separate paper. Nevertheless, the proposed model is capable of solving interoperability issues since the database has been designed with an open-BIM format (IFC). Moreover, it provides a uniform technique to capture asset data and build the database. Finally, assets can be interrogated in the BIM with the reasoning engine and management queries to take informed decision regarding operation, maintenance, servicing, repair and replacement of an asset. It would also serve as an information repository to examine the assets during decommissioning. A similar framework of a database with an open-BIM format and reasoning engine can be found in work of Hossain et al. [23].

The authors wish to acknowledge the funding provided by Nazarbayev University under "Social Policy Grant" for this research work.

\section{References}

1. E. Teicholz, "Bridging the AEC technology gap," IFMA Facility Management Journal, March-April, (2004)

2. S. A. B. Buang, "Public Asset Management in Malaysia - An Audit Perspective," N. A. Department, Ed., ed. PWTC Kuala Lumpur, Malaysia (2011). Available: https://www.audit.gov.my/docs/BM/1Ketua\%20Audit $\% 20$ Negara/Kertas $\% 20$ Pembent angan $\% 20 \mathrm{KAN} / 1$.infraasset $\% 20$ pwtc $\% 2022.2 .2011 . \mathrm{pdf}$

3. S. O. Alvarez-Romero, "Use of building information modeling technology in the integration of the handover process and facilities management," $\mathrm{PhD} \mathrm{PhD}$ Thesis, Civil Engineering, Worcester Polytechnic Institute, Worcester, MA (2014)

4. W. Chen, K. Chen, J. C. P. Cheng, Q. Wang, and V. J. L. Gan, "BIM-based framework for automatic scheduling of facility maintenance work orders," Automation in Construction, 91, pp. 15-30, (2018) 
5. B. Becerik-Gerber, F. Jazizadeh, N. Li, and G. Calis, "Application areas and data requirements for BIM-enabled facilities management," Journal of Construction Engineering and Management, 138, pp. 431-442, (2012)

6. P. E. D. Love, I. Simpson, A. Hill, and C. Standing, "From justification to evaluation: Building information modeling for asset owners," Automation in Construction, 35, pp. 208-216, (2013)

7. H. B. Cavka, S. Staub-French, and E. A. Poirier, "Developing owner information requirements for BIM-enabled project delivery and asset management," Automation in Construction, 83, pp. 169-183, (2017)

8. M. A. Hossain and J. K. W. Yeoh, "BIM for Existing Buildings: Potential Opportunities and Barriers," 3rd International Conference on Building Materials and Construction, Nha Trang, Vietnam, (2018)

9. P. Pishdad-Bozorgi, X. Gao, C. Eastman, and A. P. Self, "Planning and developing facility management-enabled building information model (FM-enabled BIM)," Automation in Construction, 87, pp. 22-38, (2018)

10. R. Eadie, M. Browne, H. Odeyinka, C. McKeown, and S. McNiff, "BIM implementation throughout the UK construction project lifecycle: An analysis," Automation in Construction, 36, pp. 145-151, (2013)

11. P. E. D. Love, J. Matthews, I. Simpson, A. Hill, and O. A. Olatunji, "A benefits realization management building information modeling framework for asset owners," Automation in Construction, 37, pp. 1-10, (2014)

12. A. Motamedi, M. M. Soltani, and A. Hammad, "Localization of RFID-equipped assets during the operation phase of facilities," Advanced Engineering Informatics, 27, pp. 566-579, (2013)

13. A. Costin, "Integration of passive RFID location tracking for real-time visualization in BIM," M.Sc. M.Sc. Thesis, Civil and Environmental Engineering, Georgia Institute of Technology, Georgia, USA, (2013)

14. K. Robbert Anton and F. Craig, "BIM: Enabling Sustainability and Asset Management through Knowledge Management," The Scientific World Journal, Vol 2013, (2013)

15. B. Giel and R. R. A. Issa, "Framework for Evaluating the BIM Competencies of Facility Owners," Journal of Management in Engineering, 32(1), p. 04015024, (2016)

16. E. A. Pärn, D. J. Edwards, and M. C. P. Sing, "The building information modelling trajectory in facilities management: A review," Automation in Construction, 75, pp. 45-55, (2017)

17. M. Kassem, G. Kelly, N. Dawood, M. Serginson, and S. Lockley, "BIM in facilities management applications: A case study of a large university complex," Built Environment Project and Asset Management, 5, pp. 261-277, (2015)

18. P. M. Teicholz and I. Foundation, BIM for Facility Managers. Hoboken, New Jersey: Wiley, (2013)

19. V. Thein. Industry Foundation Classes (IFC): BIM Interoperability Through a Vendor-Independent File Format [Online] (2011). Available: http://consultaec.com.au/white-paper-ifc-bim-interoperability-through-a-vendorindependent-file-format/

20. C. Eastman, P. Teicholz, R. Sacks, and K. Liston, BIM Handbook: A Guide to Building Information Modeling for Owners, Managers, Designers, Engineers and Contractors, Wiley, (2011) 
21. Z.-Z. Hu, J.-P. Zhang, F.-Q. Yu, P.-L. Tian, and X.-S. Xiang, "Construction and facility management of large MEP projects using a multi-Scale building information model," Advances in Engineering Software, 100, pp. 215-230, (2016)

22. Q. Lu and S. Lee, "Image-Based Technologies for Constructing As-Is Building Information Models for Existing Buildings," Journal of Computing in Civil Engineering, 31, p. 04017005, (2017)

23. M. A. Hossain, E. L. S. Abbott, and D. K. H. Chua, "Design for safety knowledgebased bim-integrated risk register system," 9th International Structural Engineering and Construction Conference: Resilient Structures and Sustainable Construction, Valencia, Spain, (2017)

24. T. Q. Nguyen, E. Abbott, D. Chua, and Y. M. Goh, "Formalizing Construction Safety Knowledge for Intelligent BIM-Based Review of Design for Safety", CIB W099 International Conference on Achieving Sustainable Construction Health and Safety, Ingvar Kamprad Design Centre (IKDC), Lund, Sweden, (2014)

25. T. W. Kang and C. H. Hong, "A study on software architecture for effective BIM/GIS-based facility management data integration," Automation in Construction, 54, pp. 25-38, (2015)

26. C. Koo and T. Hong, "Development of a dynamic operational rating system in energy performance certificates for existing buildings: Geostatistical approach and datamining technique," Applied Energy, 154, pp. 254-270, (2015)

27. A. Sattineni and T. Schmidt, "Implementation of Mobile Devices on Jobsites in the Construction Industry," Procedia Engineering, 123, pp. 488-495, (2015)

28. S. Meža, Ž. Turk, and M. Dolenc, "Component based engineering of a mobile BIMbased augmented reality system," Automation in Construction, 42, pp. 1-12, (2014) 